\title{
Post-traumatic cerebrospinal fluid Rhinorrhea, transcranial approach and Surgical Outcomes.
}

1. MBBS, FCPS

Assistant Professor Neurosurgery Jinnah Medical and Dental College Karachi.

2. MBBS, FCPS

Senior Registrar Neurosurgery Sandeman Hospital, Quetta.

3. MBBS, FCPS Fellow

Senior Registrar Neurosurgery Jinnah Postgraduate Medical Centre, Karachi.

4. MBBS, FCPS

Senior Registrar Neurosurgery Sandeman Hospital, Quetta.

5. MBBS, FCPS, MS, FRCS, CHPE Professor and HOD Neurosurgery JPMC, Karachi.

Correspondence Address:

Dr. Aurangzeb Kalhoro

Department of Neurosurgery Jinnah Medical Dental College,

Karachi.

draurangzebkalhoro@gmail.com

Article received on:

$18 / 03 / 2020$

Accepted for publication:

20/06/2020

\section{Aurangzeb Kalhoro', Abdul Samad², Farrukh Javeed ${ }^{3}$, Sher Hassan ${ }^{4}$, Lal Rehman ${ }^{5}$}

ABSTRACT... Objective: To assess the outcomes of the transcranial approach in traumatic cerebrospinal fluid rhinorrhea. Study Design: Descriptive study. Setting: J.P.M.C, Karachi. Period: 15-1-2017 to 17-7-2019. Material \& Method: Total of 57 patient were included. Including criteria were patient with a history of trauma, fall, assault, and delayed onset, however, patients presenting with spontaneous cerebrospinal fluid (CSF) rhinorrhea, brain abscess, brain spaceoccupying lesion, skull base surgery operated elsewhere were excluded. fasia lata, Pericranial flaps were used for the surgical repair. Data were analyzed on SPSS version 22.0. Result: Patients gone through the surgical approach having intradural repair in all patients, 25 (43.85\%) patients with fasia lata graft while pericranium in $32(56.1 \%)$ and the defect was filled with small bone pieces. In $38(66.6 \%)$ unilateral sub frontal approach was done while in 19 patients $(33.3$ $\% \%)$ bicoronal craniotomy was carried out. All patient had dura defected, 37 patients $(64.9 \%)$ had a fractured cribriform plate, $9(15 \%)$ patient had fovea ethmoidal fracture. $30(52.63 \%)$ had right side leak, 20 had left side leak (35\%), $7(12.28 \%)$ had bilateral from both nasals leakage. No reoperation was done. $93 \%$ procedure showed successfully. Conclusions: This method is effective with the low rate of morbidity in patients, it can be preferred for traumatic cerebrospinal fluid (CSF) leaks with the injuries associated with the brain, recurrent leak cases with a success rate of $>93 \%$.

Key words: $\quad$ Cerebrospinal Fluid (CSF) Rhinorrhea, Transcranial Approach.

Article Citation: Kalhoro A, Samad A, Javeed F, Hassan S, Rehman L. Post-traumatic cerebrospinal fluid Rhinorrhea, transcranial approach and Surgical Outcomes. Professional Med J 2021; 28(6):891-895.

https://doi.org/10.29309/TPMJ/2021.28.06.4870

\section{INTRODUCTION}

Cerebrospinal fluid (CSF) rhinorrhea is the state in which the fluid, which surrounds and protected brain, finds its way through the nose, ears or sinuses and it often occurs as a very watery runny nose. This condition only occurs when arachnoid membrane dura and the bones show laceration tearing. ${ }^{1}$ CSF rhinorrhea may develop via trauma, spontaneously, brain tumour, radiation, and many other methods. Usually, It occurs in young adults, more common presentation is rhinorrhea than Otorrhea. ${ }^{2}$ CSF leak can be spontaneous or traumatic, although the majority of traumatic leaks can stop spontaneously with no harm or it may proceed and the patient may develop pneumocephalus, headache or meningitis (7\% to $30 \%)$. The role of prophylaxis antibiotic remains controversial for traumatic CSF rhinorrhea ${ }^{3,5}$ Test available for diagnosis are nasal secretions for glucose testing, ring sign-on linen, or computed tomography cisternography (CTC), but these are less sensitive for confirming CSF leak pathway compared to high-resolution CT (HRCT) which is considered the initial study for confirmation of path \& localization. ${ }^{4}$ while Beta transferrin is the gold standard test. ${ }^{5}$ Even post-surgical CSF rhinorrhea can occur especially surgeries of the pituitary, olfactory and groove meningioma. ${ }^{6}$ Surgical intervention is a necessity, to save the patient from morbidity related to rhinorrhea. $^{7}$ Multiple approaches are available like endoscopic approach which has equally better and comparatively less invasive, bur it requires special training and instrument such procedure is available at few centres in our country ${ }^{8}$ and transcranial approach, unilateral, bo coronal and Fascia lata is reliable with and suitable for filling the defect or floor construction. ${ }^{9}$ The Glasgow coma 
scale (GCS) used as a practical approach for the assessment of impairment of conscious level to assessed as a score between 13-15 patients have a mild head injury while 9-12 of the patients are as moderate and 3-8 patients as severe help in the calculation of severity of the head injury can be assessed it. ${ }^{10}$

The rationale of our study was to focus on the outcome of the transcranial approach on patient presenting wth CSf leak at our institute.

\section{MATERIAL \& METHODS}

This study was prospective descriptive, which was conducted at neurosurgery ward of JPMC Karachi, from January 2017 to July 2019. Inclusion criteria were patient from both genders, Patients with a history of fall, trauma, assault, delayed onset, and failed to conservative management or previous surgical complication, failed endoscopic procedure for repair. Exclusion criteria were patients with brain space-occupying lesion (brain tumor), spontaneous cerebrospinal fluid (CSF) rhinorrhea, brain abscess. Consent was taken. The patient's relevant history was taken, investigations and examination plain skull X-Ray, brain MRI brain and high-resolution CT scan brain were done. Subfrontal approach, bicoronal Transcranial intradural repair approach was done. In majority cases, pericranial flap, fascia lata was used for the surgical repair. The data analyzed was done on SPSS version 22.0.

\section{RESULT}

This study was conducted among 57 patients, out of which 19 (33.33\%)patient were female and $38(66.6 \%)$ patients were male and the duration of the study was 30 months, The age ranged was between 11 years to 68 years, mean age was $40.7 \pm 14.9$ years. 36 (63.31\%) patients had road traffic injuries, $13(22.8 \%)$ patients had a history of falls, while 8 (14\%) cases were of assault. symptomatically patient presented as headache $52(91.2 \%)$, vomiting $42(73.6 \%)$ and seizures 22 (38.5\%) as shown in Table-l.

Halo sign in 53 (92.2\%) and reservoir sign 55 (96.4\%) patient were found positive on examination. The surgical approach was an intradural repair used in all patients with pericranium graft in 32 (56.1\%) and fascia lata graft in $25(43.85 \%)$ patients plus bony defects were identified in 46(75.4) patients and filled with Smallbone pieces, No other cerebrospinal fluid (CSF) drainage pathway was provided post-operative like Lumber drain. In 38(66.6\%) unilateral sub frontal approach was done while in 19 (33.3 \%\%) patients bicoronal craniotomy was performed Table-II.

All patients had dura defect, cribriform plate fracture was seen in 37 patients $(64.9 \%)$ patients, $9(15 \%)$ patient from fovea ethmoidal fracture. $30(52.63 \%)$ had right side leak, 20 had left side leak (35\%)7(12.28) had bilateral from both nasals leakage. As complication 2 (3.5\%) patient had a post-operative seizure, 1 (1.7\%) patient developed pneumocephalus and 1 (1.7\%) patient meningitis while no death was reported and no reoperation was done. $93 \%$ procedure showed successfully without any complication or mortality.

\begin{tabular}{|c|l|c|c|}
\hline s.no & Presentation & $\mathbf{n = 5 7}$ & Percentage \\
\hline 1 & Headache & 52 & $91.2 \%$ \\
\hline 2 & Vomiting & 42 & $73.6 \%$ \\
\hline 3 & Fits & 22 & $38.5 \%$ \\
\hline 4 & Meningitis & 12 & $21 \%$ \\
\hline \multicolumn{3}{|c|}{ Table-I. } \\
\hline \multicolumn{2}{|c|}{ Approach } & Number & Percentage \\
\hline Bicoronal approach & 19 & $33.3 \%$ \\
\hline Unilateral approach & 38 & $66.6 \%$ \\
\hline Cribriform plate \# & 37 & $64.9 \%$ \\
\hline & Table-II & \\
\end{tabular}

\section{DISCUSSION}

Kizmazoglu et al ${ }^{11}$ used the transcranial surgery method in his study. They reviewed 23 patients with CSF rhinorrhea. Among them 7 (30.4\%) patient had spontaneous, 11 (47.8\%) had traumatic, and iatrogenic cerebrospinal fluid (CSF) leakage in 5 (21.7\%) patients. 12 patients were approached through transcranially, 2 with an endoscopic method and 9 conservatively. the final success rate was $91.6 \%$ for the transcranial approach, compared it to our studies we don't have any patient of spontaneous cerebrospinal 
fluid (CSF) rhinorrhea and the success rate of these patients was $93.34 \%$.

Kljajić $\mathrm{V}^{12}$ performed endoscopic repair with a success rate as high as (97\%) with one patient had recurrent CSF leakage postoperatively that was post tumour surgery patient. Two patients developed hydrocephalus, one developed encephalopathy. While in our study of transcranial approach two patient had pneumocephalus and two had seizures. Rahman ZU et $\mathrm{al}^{13} 60$ patients were studied. 46 (76.6\%) males and 14 (23.3\%) were female, history of a road traffic accident in 36 $(60 \%)$, fall from height in $14(23.3 \%)$. The success rate was $90 \%$. Complications included recurrent CSF leak in $6(10 \%), 4(6.67 \%)$ had meningitis, 10 $(16.67 \%)$ patients developed pneumocephalus and $06(10 \%)$ patients with loss of smell after surgery. Similarly in our study success rate was 93.34\%, two patients had pneumocephalus and two had fits. Pillai $\mathrm{P}$ et $\mathrm{al}^{14}$ had a review of multiple studies with tension pneumocephalus (TP) of 20 patient 17 male and 23 female patients presented with most common presenting symptoms/ signs were depressed conscious level (10/20), CSF rhinorrhea ${ }^{9}$, headache ${ }^{8}$, and Seizures in 3 patients. Two deaths were reported due to tension pneumocephalus and one due to intracranial pressure (ICP) monitoring-related complication as in our study no ICP monitoring was done and no mortality was reported due to TP. Mathias T et al ${ }^{15}$ reviewed the literature and summarized that closure results in less morbidity and better long term outcome.

Hai-sheng $L$ et al $^{16}$ use of soaked cotton of fluorescein was and results were $100 \%$ accurate for diagnostic purposes in CSF rhinorrhea spontaneous in 10 patients and accidental trauma in five patients. The intraoperative use of fluorescein intranasal precise in locating CSF. It had achieved a $100 \%$ success rate in 15 patients with no recurrence. As for our centre X-Ray, brain MRI brain and high-resolution CT were done so establish the diagnosis and identify the defect.

Oakley GM et al ${ }^{17}$ were not in favour of prophylactic use of medication and lumbar drainage in his study literature was not inclined in favour of the regular role of prophylactic antibiotics, and the use of lumbar drainage while performed endoscopic procedure also supported that large defects show good results with vascularized grafts. while at our centre we did not use lumber drain but similarly used fascia lata and temporal muscle as the graft.

Mossop CM et al ${ }^{18}$ study showed that continuous leak of CSF has $20 \%-50 \%$ chance infection like empyema, meningitis, brain abscess especially with those having more than five days persistent. While in our study we had meningitis in one patient.

Cooper $\mathrm{T}^{19} 46$ patients (26 female and 20 male). Emergence of the cerebrospinal fluid (CSF) leakage documented from Posterior Cranial Fossa in three patients three patient and Middle Cranial Fossa in those 7 patients the Posterior Cranial Fossa leaks presented with meningitis compared with only 7 in the Middle Cranial Fossa group. The study also had parameters based on lumbar puncture, BMI and opening pressures. The Posterior Cranial Fossa (PCF) leakage can be corrected by using a trans mastoid method with multi-layer closure of the defect in bony and graft of fat closure of mastoid while in our study only traumatic rhinorrhea was preferred, nasal origin, in contrast, we did not account lumber puncture or BMI

\section{CONCLUSION}

This method is effective with the low rate of morbidity in patients, it can be preferred for traumatic cerebrospinal fluid (CSF) leaks with the injuries associated with the brain, recurrent leak cases with a success rate of $>93 \%$.

Copyright $\odot 20$ June, 2020.

\section{REFERENCES}

1. Zada G, Lopes MB, Mukundan S, Laws E. Spontaneous, traumatic, and postoperative CSF rhinorrhea. In Atlas of Sellar and Parasellar Lesions 2016 (pp. 517-523). Springer, Cham.

2. Junaid M, Nabi A, Khan MA, Umair M. Prevalence of cerebrospinal fluid leak in traumatic head injury at a Tertiary Care Center. Journal of Islamabad Medical \& Dental College. 2019 Sep 29; 8(3):123-6 
3. Friedman JA, Ebersold MJ, Quast LM. Post-traumatic cerebrospinal fluid leakage. World journal of surgery. 2001 Aug 1; 25(8):1062.

4. Oakley GM, Alt JA, Schlosser RJ, Harvey RJ, Orlandi RR. Diagnosis of cerebrospinal fluid rhinorrhea: an evidence $\square$ based review with recommendations. In the International forum of allergy \& rhinology 2016 Jan (Vol. 6, No. 1, pp. 8-16).

5. Mattingly JK, Ramakrishnan VR. Management of cerebrospinal fluid rhinorrhea. Recent Advances in Otolaryngology-Head \& Neck Surgery. 2017 Sep $30 ; 6: 159$.

6. Fraser S, Gardner PA, Koutourousiou M, Kubik M, Fernandez-Miranda JC, Snyderman $\mathrm{CH}$, Wang EW. Risk factors associated with postoperative cerebrospinal fluid leak after endoscopic endonasal skull base surgery. Journal of neurosurgery. $2018 \mathrm{Apr}$ $1 ; 128(4): 1066-71$.

7. Yadav YR, Parihar V, Janakiram N, Pande S, Bajaj J, Namdev H. Endoscopic management of cerebrospinal fluid rhinorrhea. Asian Journal of neurosurgery. 2016 Jul; $11(3): 183$.

8. Eraslan S, Göde S, Erdoğan U, Kaya İ, Midilli R, Karcı HB. Endoscopic cerebral spinal fluid (CSF) rhinorrhea: Clinical experiences. Eur J Rhinol Allergy. 2018;1(1):14.

9. Amir S, Qadir M, Usman M. Transcranial Dural Repair. The Professional Medical Journal. 2017 Aug 8;24(08):1232-6.

10. Patil S, Huda T, Jain SC, Pandya B, Narang R. Comparative study of the pattern of head injury in a rural community hospital and a tertiary care hospital. International Surgery Journal. 2019 Nov 26;6(12):42727.

11. Kizmazoglu C, Firat L, Ozyoruk S, Kalemci O, Karabay $\mathrm{N}$, Ozer E. Success rate and complications of cerebrospinal fluid rhinorrhea treated with a transcranial approach. Journal of Craniofacial Surgery. 2018 Nov 1; 29(8):e808-12.
12. Kljajić V, Vuleković $P$, Vlaški L, Savović $S$, Dragičević D, Papić V. Endoscopic repair of cerebrospinal fluid rhinorrhea. Brazilian journal of otorhinolaryngology. 2017 Jul 1;83(4):388-93.

13. Rahman ZU, Khan MM. Effectiveness of transcranial dural repair for early post-traumatic cerebrospinal fluid leaks. Journal of Postgraduate Medical Institute (Peshawar-Pakistan). 2018 Jul 5; 32(2).

14. Pillai P, Sharma R, MacKenzie L, Reilly EF, Beery PR. Traumatic tension pneumocephalus-Two cases and a comprehensive review of the literature. International journal of critical illness and injury science. 2017 Jan; $7(1): 58$.

15. Mathias T, Levy J, Fatakia A, McCoulED. A contemporary approach to the diagnosis and management of cerebrospinal fluid rhinorrhea. Ochsner Journal. 2016 Jun 20; 16(2):136-42.

16. Hai-sheng L, Ye-tao C, Dong W, Hui L, Yunpeng W, ShiJie W, Yan W, Guo-Qiang C, Huan-Cong Z. The use of topical intranasal fluorescein in the endoscopic endonasal repair of cerebrospinal fluid rhinorrhea. Surgical neurology. 2009 Oct 1; 72(4):341-5.

17. Oakley GM, Orlandi RR, Woodworth BA, Batra PS, Alt JA. Management of cerebrospinal fluid rhinorrhea: An evidence $\square$ based review with recommendations. In International forum of allergy \& rhinology 2016 Jan (Vol. 6, No. 1, pp. 17-24).

18. Mossop CM, Aarabi B. Diagnosis and multimodality management of skull base fractures and cerebrospinal fluid leaks. In Facial Trauma Surgery 2020 Jan 1 (pp. 79-87). Content Repository Only!.

19. Cooper T, Choy MH, Gardner PA, Hirsch BE, McCall AA. Comparison of spontaneous temporal bone cerebrospinal fluid leaks from the middle and posterior fossa. Otology \& Neurotology. 2020 Feb 1; $41(2): \mathrm{e} 232-7$. 


\begin{tabular}{|c|c|c|c|}
\hline \multicolumn{4}{|c|}{ AUTHORSHIP AND CONTRIBUTION DECLARATION } \\
\hline Sr. \# & Author(s) Full Name & Contribution to the paper & Author(s) Signature \\
\hline 1 & Aurangzeb Kalhoro & $\begin{array}{l}\text { Proposed topics and basic study } \\
\text { design, manuscript, writing \& data } \\
\text { collection. }\end{array}$ & \\
\hline 2 & Abdul Samad & $\begin{array}{l}\text { Analysis of data, Study design and } \\
\text { methodology. }\end{array}$ & \\
\hline 3 & Farrukh Javeed & $\begin{array}{l}\text { Methodology, Study design, Data } \\
\text { collection. }\end{array}$ & \\
\hline 4 & Sher Hassan & $\begin{array}{l}\text { Statical analysis, Manuscript } \\
\text { writing. }\end{array}$ & 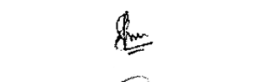 \\
\hline 5 & Lal Rehman & $\begin{array}{l}\text { Interpretation of results, Final } \\
\text { literature review. }\end{array}$ & \\
\hline
\end{tabular}

